\title{
Toxicity of Zinc Phosphide-Based Rodenticide Formulated and Sold in Nigeria
}

Enebeli Maureen Nneka ${ }^{1}$, Boisa Ndokiari ${ }^{* *}$ and Nwachoko Ndidi $^{3}$

${ }^{1}$ Department of Medical Laboratory Science, Rivers State University of Science and Technology, Port Harcourt, Nigeria

${ }^{2}$ Department of Chemistry, Rivers State University of Science and Technology, Port Harcourt, Nigeria

${ }^{3}$ Department of Biochemistry, Rivers State University of Science and Technology, Port Harcourt, Nigeria

\begin{abstract}
The toxicity of zinc phosphide-based rodenticide formulated and sold in Nigeria was investigated. Preliminary toxicity study was conducted using 24 rats and based results a dosage of zinc phosphide-based rodenticides $1 \mathrm{~g}$ to $200 \mathrm{~g}$ feed was adopted for this study. A further batch of 30 albino rats was procured for the main study. The rats were observed for period of 3 and 6 hours. At the end of the time interval, the animals were euthanized under chloroform anesthesia, blood samples were collected into sterile ethylene diaminetetraacetic acid and heparin sample bottles. Kidney and liver organs were collected and stored in $40 \%$ formaldehyde. Biochemical parameters, ALT, AST, Creatinine, urea, uric acid and potassium concentrations were enhanced 3 and 6 hours after administration of the rodenticide to the albino rats. There were also elevations for total WBC and PLT values. The enhancement of most of the biochemical and hematological parameters investigated suggest the possible failures of several organs of the rats studied. Histological slides indicated breakdown of cellular matrix compared to the slide obtained for the control. Also, there was congestion of liver sinusoids. The sinusoidal congestion found after 6 hours of ZP administration in this study may be the reason for the markedly elevated ALT and AST levels.
\end{abstract}

Keywords: Zinc phosphide; Rodenticide; Toxicity; Rats; Nigeria

\section{Introduction}

Rodenticides are pesticides that are capable of acting primarily on rodents such as rats and mice [1,2]. The risk of exposure of rodenticides to human subjects can be minimized if they are kept at designated bait stations. In most developing countries these substances are formulated with little or no regulation and applied indiscriminately. Also, most of the pesticides sold in developing countries lack information such as the active ingredients, mode of action, symptoms to be expected in an exposed individual, as well as steps to be taken as first aid measures after an accidental exposure. Most phosphide rodenticides present us with risk of both primary and secondary poisoning due to the phosphine gas [3]. Zinc phoshide, $\mathrm{Zn}_{3} \mathrm{P}_{2}$ has been mentioned in many pesticide poisoning cases [4-7]. The potency of Zinc Phospide is due to its highly poisoning phosphine gas [8]. In animal exposure, zinc phosphide is either inhaled or ingested. Some workers have suggested it blocks enzyme and protein synthesis $[8,9]$. Animals with relatively constant release of gastric acid such as rats are at greater risk than animal such as dogs whose gastric acid are released following ingestion of food [10]. Early signs of exposure may include loss of appetite, nausea, vomiting, abdominal pain, restlessness palpitation, pulmonary edema, cyanosis, hypotension, shock, cardiac arrhythmias and hypoglycemia [8]. Few authors have suggested that phosphides are damaging particularly to organs such as lungs, brains, heart liver and kidney $[4,10]$. Data on the mechanism of toxicity of zinc phoshide and its clinical effects are limited. Presently there is no known antidote for zinc phoshide poisoning. It has also been suggested that the toxicity of pesticides is dependent on formulation, exposure scenario and species. There is therefore need to study the toxicity of zinc phoshide using animals that mimics humans in their digestive tract physiology and chemistry. This study aims to study the biochemical and histopathological effects of a locally formulated zinc phosphide based rodenticides on albino rats.

\section{Materials and Methods}

A $100 \%$ survival of test animals was necessary for the study; therefore, an acute toxicity study was carried out to determine the level of tolerance to each test substance. A total of 24 healthy looking albino rats were procured from the local market. The time taken for each rodenticide to kill a rodent was obtained using different ratio of poison to commercially available feed. The animals were divided into two groups, the Control group 12 rats feed with undosed feed, the Zinc phosphide (ZP) group 12 rats feed with 3 different homogenized ratios of $Z P$ poison and feed. The preliminary toxicity study indicated the maximum survival time, as 6 hours. The preliminary toxicity study indicated the maximum survival time, as 6 hours. Based on the information obtained from the acute toxicity study, a further batch of 30 albino rats were procured for the main study. Only one homogenized ratio of feed of the poison was used. The rats were observed for period of 3 and 6 hours. At the end of the time interval, the animals were euthanized under chloroform anesthesia, blood samples were collected into sterile ethylene diaminetetraacetic acid and heparin sample bottles. Kidney and liver organs were collected and stored in $40 \%$ formaldehyde.

Biochemical parameters were analyzed following standard procedures to measure the concentration of Alanine amino tranaminase (ALT), Aspartate amino transaminase (AST), urea creatinine, uric acid, sodium and potassium ions to ascertain kidney and liver functions. Haematological parameters such as haemoglobin $(\mathrm{Hb})$, total white blood cells (WBC) and differential white blood cells (Neutrophils, Lymphocytes, Monocytes, Eosinophils and Basophils) and platelets (PLT) were also analyzed following standard procedures. Liver and kidney organs were analysed following standard procedures for tissue

*Corresponding author: Boisa Ndokiari, Department of Chemistry, Rivers State University of Science and Technology, Port Harcourt, Nigeria, Tel: +2349038858167; E-mail: boisa.ndokiari@ust.edu.ng

Received January 05, 2018; Accepted January 27, 2018; Published January 31 2018

Citation: Nneka EM, Ndokiari B, Ndidi N (2018) Toxicity of Zinc Phosphide-Based Rodenticide Formulated and Sold in Nigeria. J Environ Anal Toxicol 8: 546. doi: 10.4172/2161-0525.1000546

Copyright: @ 2018 Nneka EM, et al. This is an open-access article distributed under the terms of the Creative Commons Attribution License, which permits unrestricted use, distribution, and reproduction in any medium, provided the original author and source are credited. 
processing. The slides were stained with Haematoxylin-Eosin stain and their pictograph X400 magifications were obtained.

\section{Results}

The results of $100 \%$ survival of test animals following acute toxicity, to determine the level of tolerance to the test substance are listed in Table 1. Results of the biochemical parameters, ALT, AST, urea, creatinine, uric acid, sodium and potassium ions are provided in Table 2. Haematological parameters such, Hb, WBC, PLT and differential white blood cells (Neutrophils, Lymphocytes, Monocytes, Eosinophils and Basophils) and are provided in Table 3.

\section{Discussion}

\section{Acute toxicity study}

After three hours of oral ingestion the poison-feed ratios of 1:35 $(\mathrm{w} / \mathrm{w}), 1: 70(\mathrm{w} / \mathrm{w})$ and 1:140 (w/w) indicated 1, 1, 0 deaths, respectively (Table 1). After six hours of oral ingestion the poison-feed ratios of 1:35 $(\mathrm{w} / \mathrm{w}), 1: 70(\mathrm{w} / \mathrm{w})$ and 1:140 $(\mathrm{w} / \mathrm{w})$ indicated 3 deaths, for all dosages (Table 1). The fourth rat for 1: $140(\mathrm{w} / \mathrm{w})$ dosages died 24 hours after exposure to the poison (Table 1). Following the acute toxicity test a dosage $1 \mathrm{~g}$ poison: $200 \mathrm{~g}$ feed was adopted for the subsequent studies.

\section{Biochemical parameters}

There were enhancements in ALT and AST (Table 2). The concentrations of ALT and AST at 3 and 6 hours treatments were significantly different at $\mathrm{p}<0.05$ when compared with control. This may be due to severe cellular membrane damage and subsequent release of ALT and AST into the peripheral circulation. The enhancements of ALT and AST after the administration of Zp are consistent with previous observations by Singh et al. [11] and Frangides et al. [12]. Creatinine and urea concentration for 3 hours and 6 hours treatments also indicated elevations which may be due to cellular hypoxia resulting in acute kidney damage. The uric acid concentrations for 3 hours and 6 hours treatment indicated progressive increase when compared with control at $\mathrm{p}<0.05$. Significant increase was observed in potassium concentration of the 6 hours treatment which was significant when compared with the control value. Potassium is the most abundant intracellular cation, so following severe cellular breakdown, levels may become elevated in the extracellular fluid. According to Proudfoot, [13] in the case of human poisoning, there may be significant hypokalemia (reduced blood potassium) because ZP induces vomiting. However, rats do not have vomit reflex. These biochemical findings in $\mathrm{ZP}$ rodenticide are in agreement with those of Dogan et al. [4].

\begin{tabular}{|c|c|c|c|c|}
\hline Treatments & $\mathbf{3}$ hrs & $\mathbf{6}$ hrs & $\mathbf{1 2}$ hrs & $\mathbf{2 4}$ hrs \\
\hline 1g p: $35 \mathrm{gf}$ & 1 & 3 & & \\
\hline 1g p: $70 \mathrm{gf}$ & 1 & 3 & & \\
\hline 1g p: $140 \mathrm{gf}$ & - & 3 & & 1 \\
\hline
\end{tabular}

Table 1: Maximum surviving time for ZP treated rats in the acute toxicity test.

\section{Hematological parameters}

The ZP rodenticide treated rats had reductions in $\mathrm{Hb}$ concentrations in the first 3 hours (Table 3). This finding may be due to an acute haemolytic episode following $\mathrm{ZP}$ ingestion. This suggestion is in agreement with those of Singh et al. [11] where they indicated occurrence of microangiopathic haemolytic anaemia (MAHA) in a patient who ingested aluminium phosphide. $\mathrm{Hb}$ values in 6 hours indicated a reversal from those of 3 hours treatment. This finding may be due to normal physiological response leading to increased red cell release into the peripheral circulation. Total WBC values also indicated an increase in 3 hours and 6 hours treatments. This elevation may be due to $\mathrm{ZP}$ infiltration into the tissues and a normal physiological response of the white blood cell mechanism as first line of defense against foreign substances. This finding is in agreement with those of Signh and Khurana [11] where they indicated WBC infiltration which they suggested to be due to cellular hypoxia. There were also increases in the PLT values for the 3 hours and 6 hours treatment. This increase was considered significant at $\mathrm{p}<0.05$ when compared with control values. The elevation of PLT may be due to a possibility of disseminated intravascular coagulopathy (DIC). DIC is said to be one of the leading causes of thrombocytopenia [14]. This finding is in agreement with that of Rhaman et al. [15] where they observed in their study that ZP rodenticide induced DIC and thrombocytopenia. Increases were noted in the neutrophil count for the 6 hours treatment which may be due to increase in phagocytic activity following stress and hemolytic anaemia induced by the toxic effect of ZP (Figure 1).

\section{Histological parameters}

Liver examination of ZP group in 3 hours (Figure 2a) indicates breakdown of cellular matrix compared to the slide obtained for the control (Figure 1). This may be due to the nucleophilic nature of phosphine gas. It may also be the reason why there were increases in ALT and AST activities as noted in the biochemical results (Table 2). The cellular encroachment of portal tract may be the hallmark of an inflammatory response. In the 6 hours study, there was congestion of liver sinusoids and accumulation of cells in the liver which may be suggestive of cellular hypoxia (Figure $2 b$ ). This finding is in agreement with those of Rhaman et al. [15]. where they noted liver congestion, necrosis and hemorrhagic points alongside inflammation of the kidneys. Seleki et al. [16] also suggested that the main histological changes found after exposure to chemical poison were fine cytoplasmic vacoulation of hepatocytes and sinusoidal congestion. The sinusoidal congestion found after 6 hours of $\mathrm{ZP}$ administration in this study may be the reason for the markedly elevated ALT and AST level as indicated in Table 2. Another histological study by Mehmet et al. [17] observed that more than $50 \%$ of their human patients had congestion and the rest had both congestion and necrosis.

\section{Conclusion}

Biochemical parameters, ALT, AST, Creatinine, urea, uric acid and potassium concentrations were enhanced 3 and 6 hours after administration of the zinc phosphide-based rodenticide to the albino

\begin{tabular}{|c|c|c|c|c|c|c|c|}
\hline Groups & ALT & AST & Creat & Uric & Urea & Sodium & Potassium \\
\hline & $\mathrm{U} / \mathrm{L}$ & $\mathrm{U} / \mathrm{L}$ & $\mu \mathrm{mol} / \mathrm{L}$ & $\mu \mathrm{mol} / \mathrm{L}$ & $\mathrm{mmol} / \mathrm{L}$ & $\mathrm{mmol} / \mathrm{L}$ & $\mathrm{mmol} / \mathrm{L}$ \\
\hline CTRL & $60.0 \pm 0.00$ & $298.4 \pm 29.8$ & $33.6 \pm 4.9$ & $158.7 \pm 34.2$ & $6.5 \pm 0.3$ & $146 \pm 5.3$ \\
\hline $3 \mathrm{Hrs}$ & $101.1 \pm 13.3$ & $464.7 \pm 121.2$ & $42.6 \pm 9.9$ & $244.2 \pm 21.8$ & $7.4 \pm 0.4$ & $144 \pm 3.0$ \\
\hline $6 \mathrm{Hrs}$ & $117.0 \pm 9.0$ & $627.4 \pm 80.8$ & $62.2 \pm 10.1$ & $270.3 \pm 8.8$ & $6.2 \pm 0.2$ & $148 \pm 3.5$ & $7.5 \pm 0.65$ \\
\hline
\end{tabular}

CTRL- Control; Creat- Creatinine; ALT- Alanine amino transaminase; AST- Aspartate amino transaminase

Table 2: Mean values of biochemical parameters for Control, zinc phosphide exposed rats. 
Citation: Nneka EM, Ndokiari B, Ndidi N (2018) Toxicity of Zinc Phosphide-Based Rodenticide Formulated and Sold in Nigeria. J Environ Anal Toxicol 8: 546. doi: 10.4172/2161-0525.1000546

Page 3 of 4

\begin{tabular}{|c|c|c|c|c|c|c|c|c|}
\hline Groups & NEU & LYM & MON & EOS & BAS & $\mathrm{Hb}$ & WBC & PLT \\
\hline & \multicolumn{5}{|c|}{$\%$ Mean } & g/dL & $10 \% / L$ & $10 \% / L$ \\
\hline CTRL & $30.7 \pm 3.7$ & $59.9 \pm 1.8$ & $9.0 \pm 1.6$ & $1.0 \pm 0.2$ & $0.4 \pm 0.1$ & $14.1 \pm 0.9$ & $4.9 \pm 0.6$ & $404 \pm 11.5$ \\
\hline $3 \mathrm{Hrs}$ & $22.3 \pm 1.9$ & $64.5 \pm 6.0$ & $8.8 \pm 1.1$ & $0.8 \pm 0.1$ & $0.9 \pm 0.1$ & $12.8 \pm 0.7$ & $5.3 \pm 1.1$ & $231 \pm 16.0$ \\
\hline $6 \mathrm{Hrs}$ & $40.3 \pm 1.7$ & $53.5 \pm 1.5$ & $4.1 \pm 0.1$ & $1.8 \pm 0.3$ & $0.4 \pm 0.2$ & $14.1 \pm 1.4$ & $6.0 \pm 1.0$ & $257 \pm 11.5$ \\
\hline
\end{tabular}

CTRL- Control; NEU- Neutrophils; LYM- Lymphocytes; MON- Monocytes; EOS- Eosinophils; BAS- Basophils; Hb- Hemoglobin; WBC- Total white blood cells; PLT- Platelets Table 3: Haematological parameters for Control and Zinc Posphide.

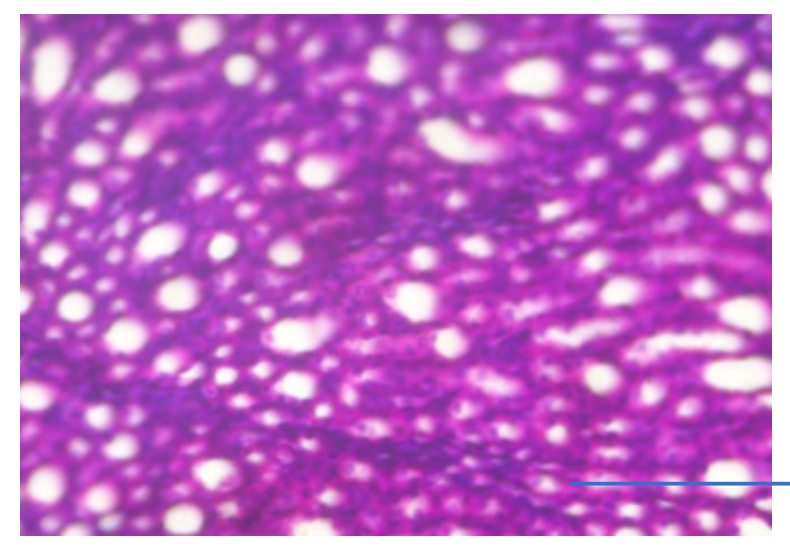

Rich healthy matrix with reticulin

Figure 1: Shows Photographic micrograph of liver organ in the control group. H and E. X400 magnification.
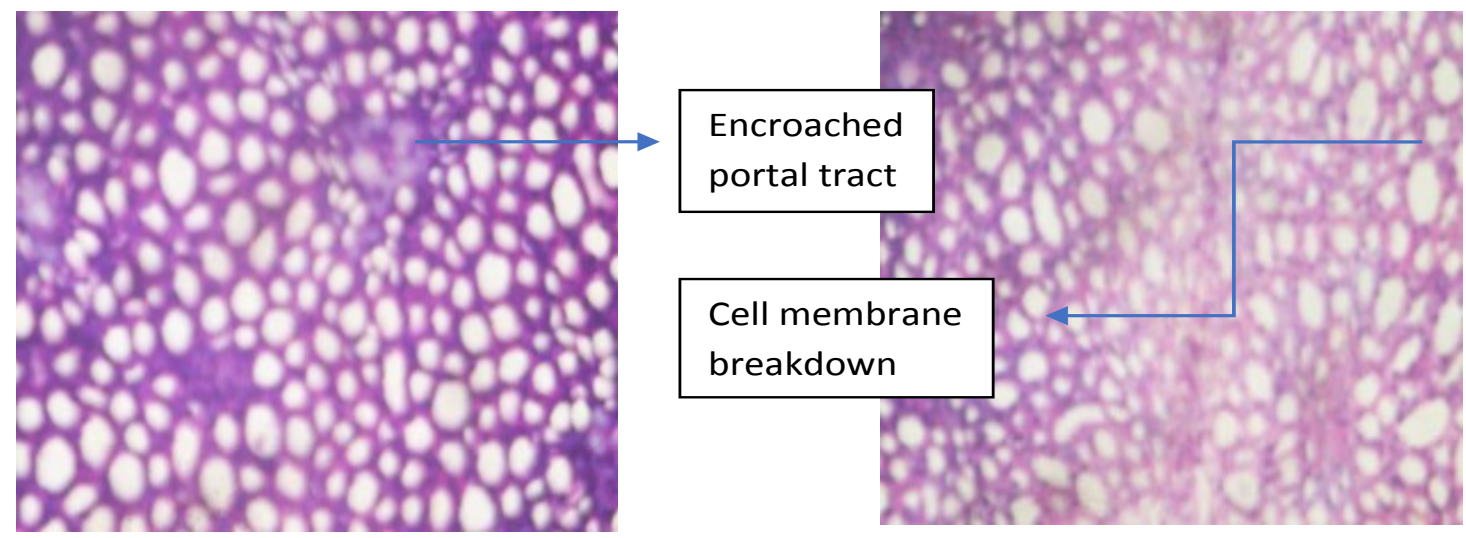

Figure 2a: Photographic micrograph of liver organ of Zinc phosphide exposed group after $3 \mathrm{hrs}$. $\mathrm{H}$ and E. X400 magnification.

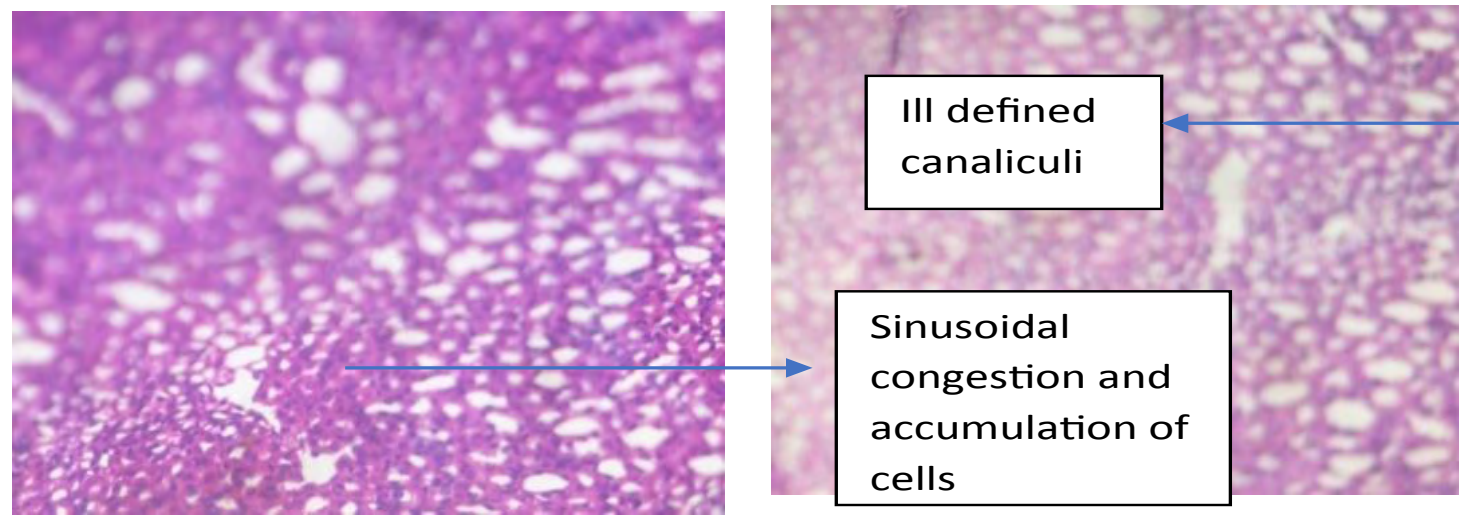

Figure 2b: Photographic micrograph of liver organ of Zinc phosphide exposed group after 6 hrs. H and E. X400 magnification. 
Citation: Nneka EM, Ndokiari B, Ndidi N (2018) Toxicity of Zinc Phosphide-Based Rodenticide Formulated and Sold in Nigeria. J Environ Anal Toxicol 8: 546. doi: 10.4172/2161-0525.1000546

Page 4 of 4

rats. There were also elevations for total WBC and PLT values, following 3 hours and 6 hours after treatment of the albino rats with zinc phosphide-based rodenticide. The enhancement of most of the biochemical and hematological parameters investigated suggest the possible failures of several organs of the rats studied. Consistent with our suggestions of possible organs malfunction, our histological slides indicated breakdown of cellular matrix compared to the slide obtained for the control. Also, there was congestion of liver sinusoids. The sinusoidal congestion found after 6 hours of $\mathrm{ZP}$ administration in this study may be the reason for the markedly elevated ALT and AST levels. Based on the data obtained from this study it may be possible speculate the possible mechanism and toxicity of the zinc phosphidebased rodenticides formulated and sold in Nigeria. It may however, be over conservative to directly extrapolate our finding to human subjects. Consequently, it may be necessary to compare data from this study to those obtained from human subject's zinc posphide-based rodenticide poisoning cases.

\section{References}

1. Leslie L (1993) Are pesticides a problem? Environmental Health Prospective 101: $578-583$.

2. United States Environmental Protection Agency (2004) Analysis of Rodenticides. Office of revention, Pesticides and Toxic Substances. United States Government Printing Office: Washington DC, USA.

3. Valchev IB, Yordanova R, Nikolas V (2008) Turkey Journal of Veterinary Animal Science 32: 237-243.

4. Marino F, Massimo SM, Bazza A, Rossi M, Muiesan ML (2014) Fatal myocardial damage due to zinc phosphide intentional ingestion. Emergency Care Journal 10: 35-36.

5. Azoury M, Levin N (1998) Identification of zinc phosphide in a falsely labeled rodenticide bait. J Forensic Sci 4: 693-695.

6. Bhat S, Kenchetty KP (2015) N-Acetyl Cysteine in the Management of Rodenticide Consumption-Life Saving? Journal of Clinical and Diagnostic Research 9: 10-13

7. Paudyal PB (2005) Poisoning: Pattern and profile of admitted cases in a hospital in central Nepal. NMA 44: 92-96.

8. Bumbrah GS, Krishan K, Kanchan T, Madhulika SM, Sodhi GS (2012) Phosphide poisoning: A review of literature. Forensic Science International 214: 1-6.

9. Sterner RT, Goldade DA, Mauldin RE (1998) Zinc phosphide residues in gray-tailed voles (Microtus canicaudus) fed fixed particles of $2 \%$ grain bait. International Biodeterioration and Biodegradation 42: 109-113.

10. Albretsen JC (2004) Zinc Phosphide. Clinical Veterinary Toxicology, pp: 456-459.

11. Singh G, Khurana D (2009) Neurology of acute organophosphate poisoning Neurology, India 57: 119

12. Frangides $C Y$, Pneumatikos IA (2002) Persistent severe hypoglycemia in acute zinc phosphide poisoning. Intensive Care Medicine 28: 223.

13. Proudfoot AT (2009) Aluminium and zinc phosphide poisoning. Clinical Toxicology 47: 89-100.

14. Hook KM, Abrams CS (2012) The loss of homeostasis in hemostasis: new approaches in treating and understanding acute disseminated intravascular coagulation in critically ill patients. Clinical and Translational Science 5: 85-92.

15. Rhaman AM, Naggar EL, Nashwa M, Mahdy EL (2011) Zinc Phosphide toxicity with a trial of tranexamic acid in its management. Journal of Advanced Research 2: 149-156.

16. Saleki S, Ardalan FA, Javidan-Nejad A (2007) Liver histopathology of fatal.

17. Mehmet TG, Halil K, Ozgur S, Murat O, Mehmet U, et al. (2013) A rare type of suicidal attempt in East Turkey: Acute Zinc Phosphide poisoning. Journal of Academic Emergency Medicine 12: 76-79. 